\title{
Discussion and Analysis on Preparations for Chinese Students Towards Effective Global Study and Career Interactions
}

\begin{abstract}
Yin Zhang*
Changzhou Institute of Industry Technology, China

*Corresponding author. Email: 347026354@qq.com

ABSTRACT

Of the more than 400,000 Chinese students who now study abroad; 235,000 came to the US; $25 \%$ of University of Washington Undergraduate enrollment for Spring 2013 were Asian. Other countries share this upward trend also. Chinese nationals comprised the largest percentage of international students at UW - my research location. In 2015 on the UW Seattle campus - 3,845 international Chinese students enrolled. The study was designed to help create more useful and enlightened programs for Chinese students pursuing degrees abroad as well as for those striving for vocations within global industries - by identifying best practices and support programs for Chinese students, universities and other institutions. This study employed a qualitative research method and in-depth interviews designed to examine the academic and overall experience of Chinese international students, domestic students, faculty and staff members at the University of Washington (UW). Research revealed five major obstacles influencing Chinese students' perception of their academic and overall well-being on campus: language, loss of filial emotional support, lack of critical and creative thinking skills, culture shock and time management inadequacies. This study recommends to both countries toward developing a more holistic approach in preparing Chinese international students and those seeking global vocations. More intensive language, emotional intelligence and inter-cultural training is vital. Partnership programs between American students and Chinese students should be established to assist in these goals.
\end{abstract}

Keywords: Cross-culture adjustment, Effective higher education, Chinese international student.

\section{BACKGROUND INFORMATION}

Of the more than 400,000 Chinese students who now study abroad; 235,000 came to the US; $25 \%$ of University of Washington Undergraduate enrollment for Spring 2013 were Asian. Other countries share this upward trend also.

Historically, there has long been an assumption that studying abroad inherently, and almost automatically, creates a transformative educational experience. But anecdotal evidence abounds that shows some study abroad experiences may be more valuable educationally than others. Much depends both on how students prepare and engage, encompassing their prestudy abroad orientations, understanding of goals, and active engagement to achieve those goals during the in-country experience. Additionally, much depends on how universities and other partners structure learning experiences for students.

\section{RESEARCH QUESTIONS}

How do Chinese students report preparing for study at the UW? What expectations do they have about studying abroad? Do they have an expectation of extensive integration into the UW generally? How are they coached for their UW experience?

How do Chinese students perceive their academic and emotional well-being in the first month of their UW experience? How do they negotiate the cultural changes they face? How do they learn to negotiate a large public American university's institutional culture, academic, and social norms? 


\section{RESEARCH METHOD}

\subsection{Qualitative Methods}

I choose to use qualitative methods for this research instead of quantitative methods because this method can serve a unique opportunity for the marginalized or disadvantaged groups to have their voices heard, which provides an opportunity to raise people's awareness of social problems (e.g., Bloor 2012).

\subsection{In-depth Interviews}

I spoke English to English native speakers and spoke both in English and Mandarin when describing the consent process with Chinese international students. And the Consent form for Chinese students also was in both Mandarin and English. Questions to Chinese International students whose native dialect is Mandarin will be in Mandarin, and for those Cantonese speakers will be in English, so that nothing can be lost in translation.

\section{PARTICIPANTS AND DATA COLLECTION}

\subsection{The Research Includes Four Groups of Participants}

There are 39 Chinese undergraduate students (25 undergraduates and 14 graduates) from almost 25 majors, 9 American domestic students (4 females and 5 males), 10 UW faculty and 20 UW staff members all throughout the campus.

\subsection{Data Collection}

According to the mandatory and approved IRB form, I used a digital voice recorder to record conversations and took notes while interviewing. The data collection period lasted from March 2015 to February 2016. This research included a variety of data, including the followings:

\section{FINDINGS}

The goals and expectations are varied from student to student and they are influenced by many aspects. There are mainly six key responses from these 39 participants and they are listed in the order of the most common to the least common ones. Moreover, differences still exist between Chinese undergraduates and graduates when talking about their goals of studying in US. Most undergraduates are concerned more about their parents directives and some of them are unfocused about the exact goals for learning in a foreign country, while all of the graduates are very clear about their own dreams here and tend to make their decision very carefully independently, believing this experience will be a critical step for them to enhance their future career and they tend to have a much stronger desire to stay in the US after graduation. When I ask them the question "Why you choose UW specifically?" Among these multiple choices answers, the top three reasons are highly ranked university, reasonable tuition, and perfect location (short distance from China and famous for advanced industries).

Most of the Chinese international students (including undergraduates and graduates) are very positive about their coming life on US campus and more than half of them have an expectation of extensive integration into the UW generally. In the interviews, nearly 95 percent of the students believe that US has the best educational system in the world and 85 percent of them would love to be involved in this wonderful learning environment on their first step to UW campus.

There are five major obstacles influencing Chinese students' perception of their academic and overall well-being on campus:

\subsection{Cultural Difference}

In the interviews, nearly all of the Chinese international students indicated that cultural differences are a major source of their difficulties

living in America at first.

Chart 1. Chinese International Students Group Division - Genders and Ages




One of the participants whose preference is to keep everything very tidy lives together with American roommates on campus. She shared a very interesting story: "Americans seems to wash everything in the washing machine together, such as underwear and sneakers together, which is really weird to Chinese people, because we think it's not sanitary to wash them together. Once I washed my underwear in the public sink which is very common habit in China and it's considered to be a good personal hygiene. But my roommate was furious at me and said that I shouldn't do it because it polluted the sink which she was really concerned about. God, can you believe it?"

\subsection{Social Habits}

"Here everyone tends to make appointments and keeps strict schedules. If you want to meet someone, you have to email them to make the arrangement first. And I find punctuality is very important here."

"I always prefer to eat Chinese food. Whenever I go to the restaurants on campus, I don't know how to order the food. Americans seem to eat too much cold and raw food here like raw broccoli and cabbages, which I cannot accept at all. I miss Chinese food a lot. Even the Chinese food here is not like the Chinese food at home. Especially for girls, for better health hot food is much better."

\subsection{Relationships with Others}

"I'm so happy that I found the Chinese students association here (refers to CSSA) so I can make friends very quickly and easily. I can find my hometown fellows here and we usually go out together, speaking in our own dialect. I like this because it helps me to release my homesickness a lot. "

"For me, the Chinese student group is a small circle or pack. We have many different individual groups like cliques on campus, which you cannot imagine. Sometimes, it's very difficult for me to face conflicts with someone here because everyone seems so inter- connected through these cliques. And I won't want to hurt our relationship so I chose to attend another association making more foreign friends to avoid that potential problems."

\subsection{Language Barriers}

When Chinese students first arrive in America, language was a major problem they encounter immediately. According to the interviews, language is a barrier in both their academic and non-academic lives. So from the first step they arrive on campus, it becomes a very serious problem for them, including both undergraduates and graduates.

"When I first came into the classroom here in UW, I could not follow what the professors were saying in the class. I did not know what to do or what to say - I just kept taking notes with a few simple words I could understand. After each class, I had to borrow my classmates' notes to catch up and I had to go to the library or stay at home to work on those materials I missed in class and try to learn by myself. The language pressure was so heavy in that first semester."

\subsection{Homesick \& Independence}

Most Chinese international students are used to living simple lives in China where academic study is the number one priority in their lives. And it's very common for parents to control and manage everything else for their children in order for them to focus completely on academic pursuits. When they come to America, they are suddenly aware that they need to learn how to live independently, such as washing clothes, cooking meals, managing their own times, or even planning their future. For some of them, it's the first time going to another country and living on their own, despite their academic acuity - their life-skills and emotional intelligence skills are seriously lacking.

"I never imagined I would suffer from homesickness before I came here. But I miss my family a lot, I seem to think constantly about my mom's cooking and

Chart 2. Expectations of Chinese Students about Studying Abroad in the US




of course her doing my laundry, I miss the crowed streets in my hometown and here the life seems so boring. I need to learn how to live independently which I seriously didn't consider before. "

\subsection{Cultural Understanding}

Most of the Chinese international students in my interviews are from mainland China, and only three came to America in their second year of Senior high school before entering UW. Without question, students who are in America longer find it easier to un- derstand and adapt to this different culture.

"It's embarrassing when a professor tells a joke in the class and everyone starts to laugh except you because you don't understand it. I used to laugh with them, but actually, I didn't catch the meaning at all."

"I like this environment of racial diversity. You can witness more cultures and you can make more friends from many different places and with many different beliefs. In China, everyone wants to pursue the same goals and tend to be envious if you have achieved what they want. Here they stick to their own rules and they

Chart 3. For Undergraduates: Main obstacles for Chinese international undergraduates on UW campus

\begin{tabular}{|l|c|c|}
\hline \multicolumn{1}{|c|}{ The main obstacles for Chinese international undergraduates on UW campus } \\
\hline \multicolumn{1}{|c|}{ Content } & $\begin{array}{c}\text { Number of Times Mentioned / } \\
\text { Students Total Number }\end{array}$ & Ratio of Frequency \\
\hline Language (Reading, writing, listening, speaking) & $23 / 25$ & 0.92 \\
\hline Cultural Understanding & $22 / 25$ & 0.88 \\
\hline Open Discussion / Presentation & $14 / 25$ & 0.56 \\
\hline Difficulty of Content & $12 / 25$ & 0.48 \\
\hline Homework & $10 / 25$ & 0.4 \\
\hline Interactions with Professors and Local Classmates & $9 / 25$ & 0.36 \\
\hline Critical Thinking Skills & $7 / 25$ & 0.28 \\
\hline Plagiarism & $6 / 25$ & 0.24 \\
\hline Time Management & $2 / 25$ & 0.08 \\
\hline Resources on Campus & $1 / 25$ & 0.04 \\
\hline
\end{tabular}

Chart 4. For Graduates: Main obstacles for Chinese international graduates on UW campus

\begin{tabular}{|l|c|c|}
\hline \multicolumn{1}{|c|}{ The main obstacles for Chinese international graduates on UW campus } \\
\hline \multicolumn{1}{|c|}{ Content } & $\begin{array}{c}\text { Number of Times Mentioned / } \\
\text { Students Total Number }\end{array}$ & Ratio of Frequency \\
\hline Language (listening, speaking, reading, writing) & $12 / 14$ & 0.85 \\
\hline Difficulty of Content & $10 / 14$ & 0.71 \\
\hline Independence & $10 / 14$ & 0.71 \\
\hline Cultural Understanding & $8 / 14$ & 0.57 \\
\hline Homework & $7 / 14$ & 0.50 \\
\hline Interactions with Professors and Local Classmates & $7 / 14$ & 0.50 \\
\hline Plagiarism & $4 / 14$ & 0.29 \\
\hline Resources on Campus & $2 / 14$ & 0.07 \\
\hline Time Management & $1 / 14$ & 0.14 \\
\hline
\end{tabular}


are not easy to change because of other influences."

\section{CONCLUSION}

How can American universities improve support services for Chinese international students? One of the primary problem issues for undergraduates is making the selection of a major for their first year of study. The curriculum paradigm in China differs in that every freshman begins his/her university learning experience with a pre-arranged major.

Suggestions for American universities are mainly related to the following aspects:

To enhance the academic aptitude of Chinese students: consider providing more training opportunities in English reading and writing; providing more academic direction in critical thinking by giving them more fundamental materials to discuss; encouraging them to give more presentations on the topics that they are more familiar with; allowing them more time to think about the questions posed in class and encouraging them to express themselves.

In order to improve the Chinese students' experience on campus: consider providing a workshop informing Chinese undergraduates at the very beginning with specific details (written in Chinese for future reference) of the services and helpful resources on campus; if possible, setting up a networking system that encourages American students to partner with Chinese students one-to-one so whenever they have specific questions, they can have an immediate individual resource; encouraging them to pay more attention to their psychological and emotional status and offer instruction in coping more effectively with high pressure situations. There is a critical need for them to feel more comfortable when it's necessary to ask for help.

In preparation for language proficiency, academic performance and independent living skills: it is suggested that schools provide more intensive training in English communication, notably in listening, speaking, reading and writing; encouraging greater self confidence, more cultural tolerance and understanding diversity, with an emphasis on critical and creative thinking; learning cross-cultural conflict resolution methods and more intensive intra-personal communication skills.

For Chinese students, they should strive to learn more about what is involved in studying in the U.S. educational system and try to get familiar with the academic policies and requirements of American universities before they arrive. Besides English language study, understanding and embracing cultural differences, improving study habits, emotional control skills, debating skills, life-management skills and relationship skills are also very important. Additionally, methods of self-analysis about the true feasibility and inherent obstacles of studying abroad should be clearly understood prior to arrival in the foreign country. Studying abroad should be not only a happy adventure, but also a critical landmark in personal development for Chinese students.

\section{ACKNOWLEDGMENTS}

The project is supported by Jiangsu Qing Lan Project

\section{REFERENCES}

[1] Abouserie, R. (1994). Sources and levels of stress in relation to locus of control and self-esteem in university students. Educational Psychology: An International Journal of Experimental Educational Psychology

[2] Bloor, M. (2012). Chapter 14: Addressing Social Problems through Qualitative Research. In Silverman, D. (ed.) Qualitative Research, 3rd edition (pp.221- 237). Sage.

[3] Clément, R. (1980). Ethnicity, contact and communicative competence in and second language. In H. Giles, W. P. Robinson, \& P. M. Smith (Eds.), Language: Social Psychological Perspectives. Oxford: Pergamon Press.

[4] Glesne, C. (2005). Becoming qualitative researchers: an Introduction. New York: Longman.

[5] Kagitçibasi, C. (2005). Autonomy and relatedness in cultural context: Implications for self and family. Journal of Cross-Cultural Psychology.

[6] Hall, M. E. L., Edwards, K. J., \& Hall, T. W. (2006). The role of spiritual and psychological development in the cross-cultural adjustment of missionaries. Mental Health, Religion \& Culture.

[7] Hammersley, M., \& Atkinson, P. (2010). Ethnography: Principles in practice. London: Routledge.

[8] Mori, S. (2000). Addressing the mental health concerns of international students. Journal of Counseling and Development

[9] Norton, B. (2013). Identity and language learning: Gender, ethnicity and educational change (the second edition). Harlow, UK: Person Education.

[10] Poyrazli, S., Kavanaugh, P. R., Baker, A., \& Al Timimi, N. (2004). Social support and demographic correlates of acculturative stress in internationals students. Journal of College Counseling 
[11] Toyokawa, T., \& Toyokawa, N. (2002). Extracurricular activities and the adjustment of Asian international students: A study of Japanese students. International Journal of Intercultural Relations.
[12] Yin, R. K. (2003). Case study research, design and methods, 3rd ed. Newbury Park: Sage Publications. 